Mixed-Mode Decohesion Elements for Analyses of Progressive Delamination

\author{
Carlos G. Dávila \\ NASA Langley Research Center \\ Hampton, VA \\ Pedro P. Camanho, Marcelo F. de Moura \\ University of Porto, Portugal
}

Paper AIAA-01-1486

42nd AIAA/ASME/ASCE/AHS/ASC Structures, Structural Dynamics and Materials Conference

Seattle, Washington

April 16-19, 2001 


\title{
MIXED-MODE DECOHESION ELEMENTS FOR ANALYSES OF PROGRESSIVE DELAMINATION
}

AIAA-01-1486

\author{
Carlos G. Dávila* \\ NASA Langley Research Center, Hampton, VA 23681 \\ Pedro P. Camanho ${ }^{\dagger}$ and Marcelo F. de Moura ${ }^{\dagger}$ \\ University of Porto, Portugal
}

\begin{abstract}
$\underline{\text { Abstract }}$
A new 8-node decohesion element with mixedmode capability is proposed and demonstrated. The element is used at the interface between solid finite elements to model the initiation and propagation of delamination. A single displacement-based damage parameter is used in a strain softening law to track the damage state of the interface. The method can be used in conjunction with conventional material degradation procedures to account for inplane and intra-laminar damage modes. The accuracy of the predictions is evaluated in single mode delamination tests, in the mixed-mode bending test, and in a structural configuration consisting of the debonding of a stiffener flange from its skin.
\end{abstract}

\section{Introduction}

Delamination is one of the predominant forms of failure in laminated composites due to the lack of reinforcement in the thickness direction. Delamination as a result of impact or a manufacturing defect can cause a significant reduction in the compressive loadcarrying capacity of a structure. The stress gradients that occur near geometric discontinuities such as ply drop-offs, stiffener terminations and flanges (Figure 1), bonded and bolted joints, and access holes promote delamination initiation, trigger intraply damage mechanisms, and cause a significant loss of structural integrity.

The fracture process of high performance composite laminates is quite complex, involving not only interlaminar damage (delamination), but also intralaminar damage mechanisms (e.g. matrix cracking, fiber fracture). For effective predictive capabilities, progressive failure analysis tools for all modes of failure are needed.

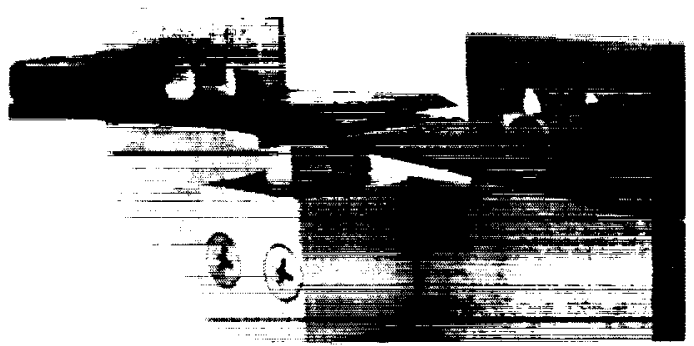

Figure 1. Experiment illustrating stiffener-flange debonding.

The objective of this paper is to present a method to simulate progressive debonding or delamination based on decohesion elements. A criterion for mixedmode delamination is proposed. The effectiveness of the method is assessed with an emphasis on its ease of use and the accuracy of the predictions.

\section{Numerical Simulation of Delamination}

The study of delamination mechanics may be divided into the study of delamination initiation and the analysis of delamination propagation. Delamination initiation analyses are usually based on stresses and use criteria such as the quadratic interaction of the interlaminar stresses in conjunction with a characteristic distance $^{1.2}$. The characteristic distance is an averaging length that is a function of geometry and material properties, so its determination always requires extensive testing.

Most analyses of delamination growth apply a fracture mechanics approach and evaluate strain energy release rates $G$ for self-similar delamination growth. The $G$ values are usually evaluated using the virtual crack closure technique (VCCT) proposed by Rybicki and Kanninen ${ }^{3}$. The VCCT technique is based on Irwin's assumption that when a crack extends by a small

\footnotetext{
* Aerospace Engineer, Analytical and Computational Methods Branch. Member, AIAA.
}

$\dagger \quad$ Assistant Professor, Department of Mechanical Engineering, University of Porto.

Copyright $\odot 2001$ by the American institute of Aeronautics and Astronautics, Inc. No copyright is asserted in the United States under Title 17 , U.S. Code. The U.S. Government has a royalty-free license to exercise all rights under the copyright claimed herein for Government Purposes. All other rights are reserved by the copyright owner. 
amount, the energy released in the process is equal to the work required to close the crack to its original length. The Mode I, Mode II, and Mode III energy release rates can then be computed from the nodal forces and displacements obtained from the solution of a finite element model. The approach is computationally effective since the energy release rates can be obtained from only one analysis.

In the present paper, an approach is proposed that is well suited to nonlinear progressive failure analyses where both ply damage and delaminations are present. The approach consists of placing interfacial decohesion elements between composite layers. A decohesion failure criterion that combines aspects of strength-based analysis and Fracture Mechanics is used to simulate debonding by softening the element. The proposed constitutive equations for the interface are phenomenological mechanical relations between the tractions and interfacial separations. With increasing interfacial separation, the tractions across the interface reach a maximum, decrease, and vanish when complete decohesion occurs. The work of normal and tangential separation can be related to the critical values of energy release rates.

Decohesion can be implemented as a material response such as the Dudgale-Barenblatt (D-B) type cohesive zone ${ }^{4}$. The $D-B$ cohesive zone model was first applied to the analysis of concrete cracking by Hillerborg et $\mathrm{al}^{5}$. The concept has also been used by Needleman ${ }^{6}$ to simulate fast crack growth in brittle solids. Needleman considered that cohesive zone models are particularly attractive when interfacial strengths are relatively weak when compared with the adjoining material, as is the case in composite laminates.

In order to predict the initiation and growth of delaminations, an 8-node decohesion element shown in Fig. 2 was developed and implemented in the ABAQUS finite element code. The development of this element is based on prior work ${ }^{7,8}$. The decohesion element is used to model the interface between sublaminates or between two bonded components. The element consists of a zero-thickness volumetric element in which the interpolating shape functions for the top and bottom faces are compatible with the kinematics of the elements that are being connected to it. The material response built into the element represents damage using a cohesive zone ahead of crack tip to predict delamination growth. The concept of interface elements has been used in different types of problems: compression after impact $^{7.9}$, damage growth from discontinuous plies ${ }^{10}$, and diametrical compression of composite cylinders ${ }^{11}$.

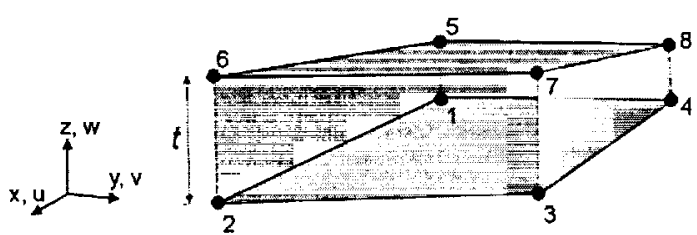

Figure 2. Eight-node decohesion element; $t \approx 0$.

\section{Constitutive Equations}

The need for an appropriate constitutive equation in the formulation of the interface element is fundamental for an accurate simulation of the interlaminar cracking process. A constitutive equation is used to relate the stress $\sigma$ to the relative displacement $\delta$ at the interface. Some strain softening models that have been proposed are shown in Fig. 3 and include: linear elastic-perfectly plastic; linear elastic-linear softening; linear elastic-progressive softening; linear elasticregressive softening; and Needleman ${ }^{6}$. One characteristic of all softening models is that the cohesive zone can still transfer load after the onset of damage ( $\delta^{D}$ in Figure 3 ). For pure Mode I, II or III loading, after the interfacial normal or shear stresses attain their respective interlaminar tensile or shear strengths, the stiffnesses are gradually reduced to zero. The area under the stress-relative displacement curves is the respective (Mode I, II or III) fracture energy. Using the definition of the $J$ integral proposed by Rice ${ }^{12}$, it can be shown that for small cohesive zones,

$$
\int_{0}^{\delta^{F}} \sigma(\delta) d \delta=G_{C}
$$

where $G_{\boldsymbol{c}}$ is the critical energy release rate for a particular mode, and $\delta^{F}$ is the corresponding relative displacement at failure $\left(\delta_{p p}, \delta_{p r o}, \delta_{l i n} \delta_{N e}\right.$, or $\delta_{r e}$ in Figure 3).

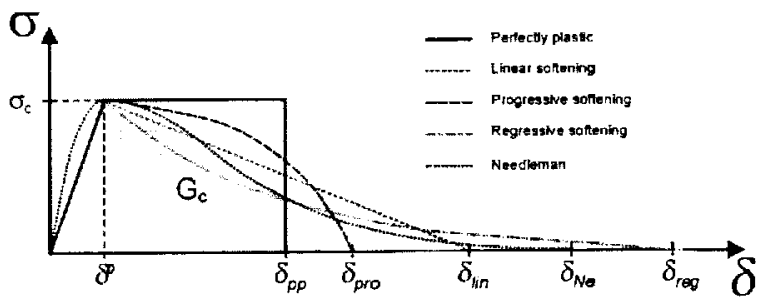

Figure 3. Strain softening constitutive models.

\section{Bilinear Softening Model}

The linear elastic-linear softening (bilinear) model is the simplest to implement, and is most commonly used $^{7-9,11,13-15}$. The double cantilever beam test shown 
in Figure 4 illustrates the material response. Point 1 in Figure 4 is subjected to a low tensile load that is within the linear elastic range. A high initial stiffness $K_{p}$ (penalty) holds the top and bottom faces of the interface element together. Point 2 represents the onset of damage. In single-mode delamination, the stress at point 2 is equal to the corresponding interlaminar strength of the material, $\sigma_{c}$. As the relative displacement increases, the interface accumulates damage and the stress is lower than the strength (point 3). The energy released at point 3 is the area of the triangle $0-2-3$. The energy released is the most important component of the failure criterion described in the next section. If the load were to reverse, point 3 would unload to the origin, as shown in the figure.

The critical value of the energy release rate is attained at point 4 . For any relative displacement larger than point 4 , the interface does not carry any tensile or shear loads (point 5). In other words, at point 4 all the available interfacial fracture energy has been completely consumed. Note that when modeling delamination with a softening response, the delamination tip is not defined explicitly. While the onset of damage occurs at point 2 in Figure 4, the delamination tip could be defined as the point where the tractions at the interface are zero, which is point 4 .

The softening response illustrated in Figure 4 is representative of the tension or the shear response but not compression. It is assumed that compression loads do not cause delamination or softening, and the effect of compression on damage of the interface was neglected in the present work.

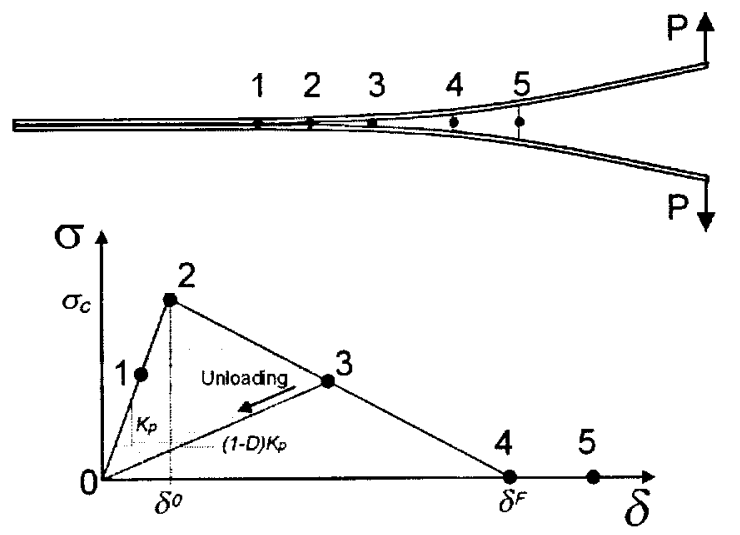

Figure 4. Bilinear constitutive model.

The problem of contact of the crack faces after failure is addressed by re-applying the normal penalty stiffness. The process of reapplying the normal stiffness when interpenetration is detected is typical of solution procedures of contact problems using penalty methods in a constrained variational formulation.
The concept of decohesion zones to simulate delamination growth in composites is usually implemented by means of interface elements connecting the individual plies of a composite laminate. Decohesion elements can model the discontinuity introduced by the growth of delaminations. They can be divided into two main groups: continuous interface elements and point interface elements. Several types of continuous interface elements have been proposed, ranging from plane interface elements with zero thickness connecting solid elements ${ }^{7-9}$; plane interface elements with finite thickness connecting shell elements ${ }^{11}$; line interface elements ${ }^{10,15,16}$; and spring interface elements that connect pairs of nodes ${ }^{13,14}$.

The bilinear interfacial constitutive response shown in Figure 4 can be implemented as follows:

i) $\delta<\delta^{0} \Rightarrow$ the constitutive equation is given by:

$$
\sigma=K_{p} \delta
$$

ii) $\delta^{0} \leq \delta<\delta^{F} \Rightarrow$ the constitutive equation is given by:

$$
\sigma=(1-D) K_{p} \delta
$$

where $D$ represents the damage accumulated at the interface, which is zero initially, and reaches $I$. when the material is fully damaged.

iii) $\delta \geq \delta^{F} \Rightarrow$ all the penalty stiffnesses is set equal to zero. If crack closure is detected, interpenetration is prevented by reapplying only the normal stiffness. Frictional effects are neglected.

The properties required to define the bilinear interfacial softening behavior are the initial stiffness (penalty) $K_{P}$, the fracture energies $G_{I C}, G_{I I C}$, and $G_{I I C}$ and the corresponding nominal interlaminar tensile and shear strengths, $T$ and $S$. The accuracy of the analysis depends on the penalty stiffness $K_{P}$ that is chosen. High values of $K_{P}$ avoid interpenetration of the crack faces but can lead to numerical problems. Several values have been proposed for the penalty stiffness, $K_{p}: 10^{7} \mathrm{~N} / \mathrm{mm}^{3}$ [Ref. 9], 5.7 $10^{7} \mathrm{~N} / \mathrm{mm}^{3}$ [Ref. 16], $10^{8} \mathrm{~N} / \mathrm{mm}^{3}$ [Ref. 13]. Other authors have determined the value for the penalty stiffness as a function of the interface properties. Daudeville et al. ${ }^{17}$ have modeled the interface as a resin rich zone of small thickness, $t_{i}$, and proposed a penalty stiffnesses defined as:

$$
K_{P}^{I}=\frac{E_{3}}{t_{i}} ; K_{P}^{I I}=\frac{2 G_{13}}{t_{i}} ; K_{P}^{I I I}=\frac{2 G_{23}}{t_{i}}
$$

where $G_{23}, G_{13}$, and $E_{3}$ are the elastic moduli of the resin rich zone. After a substantial number of numerical 
experiments, Moura determined that a penalty stiffnesses of only $10^{6} \mathrm{~N} / \mathrm{mm}^{3}$ for all modes produces essentially the same results while avoiding potential convergence problems during the nonlinear procedure.

In order to fully define the interfacial behavior, the unloading response must be specified. Petrossian et al. ${ }^{16}$ have proposed an unloading curve with a slope corresponding to Hooke's law. Such a procedure, typically used in the formulation of plasticity problems, would lead to the use of the same penalty stiffness when reloading and to permanent relative displacements along the interface when the load reverts to zero. Crisfield et al. ${ }^{15,16}$ and Daudeville ${ }^{17}$, on the other hand, have proposed that with reversing strains the material unloads directly toward the origin, as shown in Figure 4. The assumption is that during reloading the interfacial stiffness is lower than the original (undamaged) stiffness. Such a procedure simulates the effects of the previous damage mechanisms that occurred along the interface and was therefore adopted in the present work.

\section{Mixed Mode Delamination Criterion}

- In structural applications of composites, delamination growth is likely to occur under mixedmode loading. Therefore, a general formulation for interface elements must deal with mixed-mode delamination growth problems.

Under pure Mode I, II or III loading, the onset of damage at the interface can be determined simply by comparing the stress components with their respective allowables. Note that the onset of damage does not imply the initiation of delamination, since the tractions closing the crack at onset are at their maximum value. Under mixed-mode loading, however, damage onset may occur before any of the stress components involved reach their respective allowables.

A mixed-mode criterion is proposed here that is based on a few simplifying assumptions. Firstly, it is assumed that delamination initiation can be predicted using the quadratic failure criterion

$$
\sqrt{\left(\frac{\sigma_{z}}{T}\right)^{2}+\left(\frac{\tau_{x z}}{S}\right)^{2}+\left(\frac{\tau_{y z}}{S}\right)^{2}}=1
$$

where $\sigma_{z}$ is the transverse normal tensile stress and $\tau_{x z}$ and $\tau_{\mathrm{yz}}$ are the transverse shear stresses. $T$ and $S$ are the nominal normal tensile and shear strengths, respectively.
The delamination mechanisms in Mode II and Mode III are assumed to be the same. Therefore, Mode III can be combined with Mode II by using a total tangential displacement $\delta_{\|}$defined as the norm of the two orthogonal tangential relative displacements $\delta_{x}$ and $\delta_{y}$ as

$$
\delta_{I I}=\sqrt{\delta_{x}^{2}+\delta_{y}^{2}}
$$

The total mixed-mode relative displacement $\delta_{m}$ is defined as

$$
\delta_{m}=\sqrt{\delta_{z}^{2}+\delta_{I I}^{2}}
$$

where $\delta_{z}$ is the relative opening (Mode I) displacement. Using the same penalty stiffness in Modes I and II, the interlaminar stresses are

$$
\begin{aligned}
& \sigma_{z}=K_{P} \delta_{z} \\
& \tau_{x z}=K_{P} \delta_{x} \\
& \tau_{y z}=K_{P} \delta_{y}
\end{aligned}
$$

The single-mode failure initiation displacements are then

$$
\begin{aligned}
& \delta_{l}^{0}=T / K_{P} \\
& \delta_{I I}^{0}=S / K_{P}
\end{aligned}
$$

where $T$ and $S$ are the nominal tensile and shear strengths of the interface. If the relative opening displacement $\delta_{z}$ is not zero, the mode mixity can be expressed by

$$
\beta=\frac{\delta_{l l}}{\delta_{z}}
$$

The mixed-mode damage initiation displacement is obtained by substituting Eqs. 6-10 into 5, which gives:

$$
\delta_{m}^{0}=\delta_{I}^{0} \delta_{I I}^{0} \sqrt{\frac{1+\beta^{2}}{\left(\delta_{I I}^{0}\right)^{2}+\left(\beta \delta_{I}^{0}\right)^{2}}}
$$

A quadratic interaction between the energy release rates was selected. The interaction law defines the total interfacial fracture corresponding to the point where the interface is unable to transfer tensile or shear loads. The quadratic interaction criterion can be expressed as

$$
\sqrt{\left(\frac{G_{l}}{G_{l c}}\right)^{2}+\left(\frac{G_{l l}}{G_{l l}}\right)^{2}} \leq 1
$$


where the equality is only satisfied at failure. For the bilinear stress-displacement softening law assumed here, the critical energy release rates in Mode $I$ and Mode II are simply the areas under the triangle $0-2-4$ in Figure 4.

$$
G_{I c}=\frac{T \delta_{l}^{F}}{2} \quad ; \quad G_{I l c}=\frac{S \delta_{I I}^{F}}{2}
$$

The Mode I and Mode II energies released are computed from the area of the shaded triangle $0-2-3$ in Figure 4, which is

$$
\begin{aligned}
& G_{I}=G_{l r}-\frac{\delta_{l}^{F} \delta_{l}^{0} K_{P}\left(\delta_{z}-\delta_{I}^{F}\right)}{2\left(\delta_{I}^{0}-\delta_{l}^{F}\right)} \\
& G_{I I}=G_{I r}-\frac{\delta_{I I}^{F} \delta_{I I}^{0} K_{P}\left(\delta_{I I}-\delta_{I I}^{F}\right)}{2\left(\delta_{I I}^{0}-\delta_{I I}^{F}\right)}
\end{aligned}
$$

where $\delta_{I}^{F}$ and $\delta_{l l}^{F}$ are the ultimate opening and tangential displacements, respectively. The ultimate opening displacements are calculated using Eqs. 9 and 13. Using the definition of the mixed-mode relative displacement $\delta_{m}$ in Eq. 7 and the mode mixity ratio $\beta$ given by Eq. 10 , one can solve for the ultimate relative displacement $\delta_{m}^{F}$ by substituting Eqs. 14 into the equality of Eq. 12. After some manipulation, the result is a quadratic equation that has only one positive root, which is:

$$
\begin{aligned}
\delta_{m}^{F}= & \frac{\sqrt{1+\beta}}{\beta^{2}\left(\delta_{I}^{0 F}\right)^{2}+\left(\delta_{I I}^{O F}\right)^{2}} \times \\
& \left(\begin{array}{l}
\delta_{l}^{0}\left(\delta_{I I}^{0 F}\right)^{2}+\beta \delta_{I I}^{0}\left(\delta_{I}^{O F}\right)^{2} \\
+\delta_{I}^{0 F} \delta_{I I}^{O F} \sqrt{\left(\delta_{I I}^{O F}\right)^{2}-\left(\delta_{I I}^{0}\right)^{2}+2 \beta \delta_{I}^{0} \delta_{I I}^{0}-\beta^{2}\left(\delta_{l}^{0}\right)^{2}+\beta^{2}\left(\delta_{l}^{0 F}\right)^{2}}
\end{array}\right)
\end{aligned}
$$

where $\delta_{i}^{0 F}=\delta_{l}^{F}-\delta_{l}^{0}$ and $\delta_{\| \prime}^{0 F}=\delta_{l l}^{F}-\delta_{l l}^{0}$, which are calculated using Eqs. 9 and 13 and the following required material parameters: the penalty stiffness $K_{p}$, the interlaminar strengths $T$ and $S$, and the material toughnesses $G_{I_{c}}$ and $G_{I I r}$.

In summary, the mixed mode softening law presented above is a single-variable response similar to the bilinear single-mode law illustrated in Figure 4 . Only one state variable, the relative displacement variable $\delta_{m}$. is used to track the damage at the interface. By recording the highest value attained by $\delta_{m}$, the unloading response is such as shown in Figure 4 . The displacements for initiation $\delta_{m}^{0}(\beta)$ and ultimate failure $\delta_{m}^{F}(\beta)$ are functions of the mode mixity $\beta$ and are computed with Eqs. 11 and 15, respectively.

A mixed-mode softening law can be illustrated in a single 3D map by representing Mode I on the 2-3 plane, and Mode II in the 1-3 plane, as shown in Figure 5. The triangle $0-\mathrm{C}-\mathrm{D}$ is the bilinear strain response in Mode $\mathrm{I}$. It can be observed that the tensile strength $T$ is lower than the shear strength $S$, and the ultimate displacement in shear is lower than in tension. In this threedimensional map, any point on the 0-1-2 plane represents a mixed-mode relative displacement.

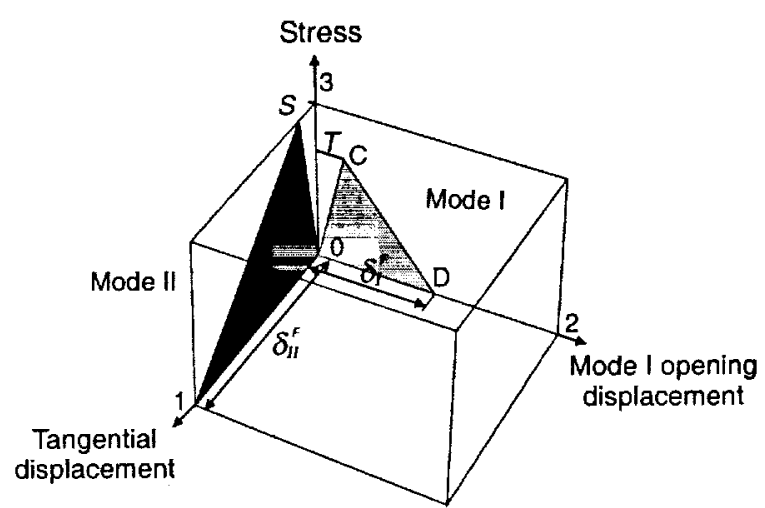

Figure 5. Combined plot of single-mode bilinear material responses.

The map of all softening responses under mixed mode is illustrated in Figure 6 . The curve $F I$ represents the stresses resulting from the displacements at the onset of damage given by Eq. 11 , while the curve labeled $G$ represents the ultimate relative displacements calculated with Eq. 15. The triangle $O-A-B$ is the bilinear softening law for a mixed-mode relative displacement of $\delta_{m}$. The triangle $O-A-B$ is identical to the triangle $0-2-3$ in Figure 4 . For reference, the triangle $0-\mathrm{C}-\mathrm{D}$ in Figure 6 is the Mode I bilinear softening response. It can also be observed that the effect of compression on the material response is neglected.

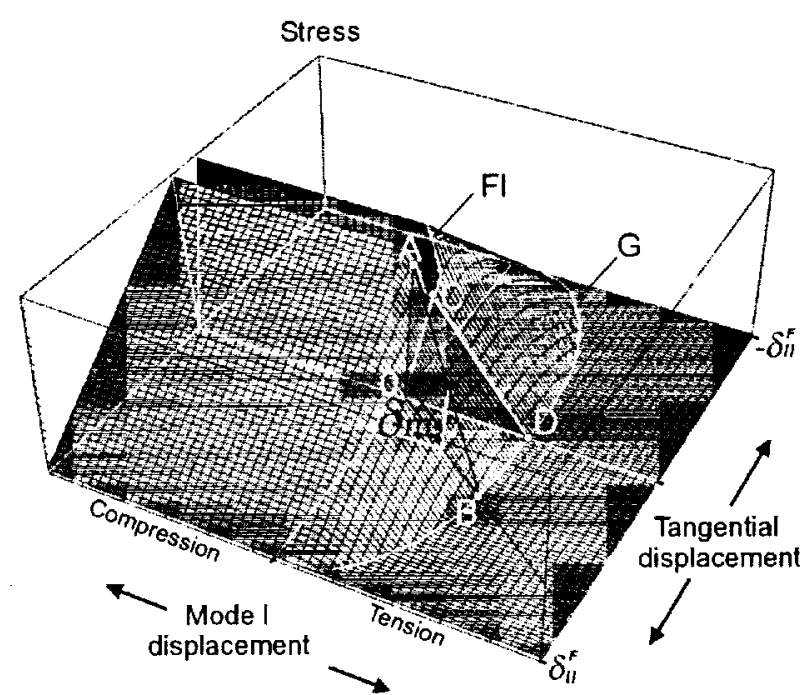

Figure 6. Map of strain softening response for mixed mode delamination. 


\section{Element Formulation}

The element stiffness matrix is based on the standard isoparametric linear Lagrangian interpolation functions for three-dimensional (8-node) elements. The relative displacements between the top and the bottom faces of the element in a local coordinate frame $x-y-z$ are

$$
\left\{\begin{array}{l}
\delta_{z} \\
\delta_{x} \\
\delta_{y}
\end{array}\right\}=\left\{\begin{array}{l}
w \\
u \\
v
\end{array}\right\}_{t o p}-\left\{\begin{array}{l}
w \\
u \\
v
\end{array}\right\}_{b o t}=\mathbf{B} \mathbf{U}
$$

where $\mathbf{B}$ is the matrix relating the element's degrees of freedom $\mathbf{U}$ to the relative displacements between the top and bottom interfaces.

The three-dimensional form of Eq. 3 is

$$
\boldsymbol{\sigma}=(\mathbf{I}-\mathbf{D}) \mathbf{C} \boldsymbol{\delta} \text { or }\left\{\begin{array}{l}
\sigma_{z} \\
\tau_{x z} \\
\tau_{y z}
\end{array}\right\}=(\mathbf{I}-\mathbf{D}) \mathbf{C}\left\{\begin{array}{l}
\delta_{z} \\
\delta_{x} \\
\delta_{y}
\end{array}\right\}
$$

where $\mathbf{I}$ is the identity matrix, $\mathbf{C}$ is the undamaged constitutive matrix

$$
\mathbf{C}=\left[\begin{array}{ccc}
K_{P} & 0 & 0 \\
0 & K_{P} & 0 \\
0 & 0 & K_{P}
\end{array}\right]
$$

and $\mathbf{D}$ is a diagonal matrix representing the damage accumulated at the interface:

$$
\mathbf{D}=\left[\begin{array}{lll}
d & 0 & 0 \\
0 & d & 0 \\
0 & 0 & d
\end{array}\right]
$$

The term $d$ on the diagonal is the damage parameter, which is a nonlinear function of $\delta_{m}^{\max }$, the highest mixed-mode relative displacement experienced by the material

$$
d=\frac{\delta_{m}^{F}\left(\delta_{m}^{\max }-\delta_{m}^{0}\right)}{\delta_{m}^{\max }\left(\delta_{m}^{F}-\delta_{m}^{0}\right)}
$$

Using the maximum value of the relative displacement rather than the current value prevents healing of the interface. $\delta_{m}^{\max }$ is the only state variable that needs to be stored in the database to track the accumulation of damage.

The minimization of the potential energy subjected to the kinematic constraints of Eq. 17 leads to the usual integral over the area of the element, which gives the following element stiffness ${ }^{7,8}$ :

$$
\mathbf{K}_{\text {elem }}=\int_{A} \mathbf{B}^{T}((\mathbf{I}-\mathbf{D}) \mathbf{C}) \mathbf{B} d A
$$

The integration is performed numerically using a Newton-Cotes integration, which has been shown to perform better than Gaussian integration in problems involving strain softening ${ }^{13,14}$. The integration points of a zero-thickness decohesion element coincide with the four corners of the element. Since the material softening response is evaluated at each integration point, the element can soften one corner at a time, giving it the potential to model non self-similar delamination growth.

\section{Nonlinear Solution}

The nonlinear solution of the problems presented here was performed using standard ABAQUS procedures. However, the softening nature of the interface element constitutive equation causes convergence difficulties in the solution of the analysis. The solution of most problems requires tens of load increments averaging 200-300 iterations per increment. Such a large number of iterations could render the solution of most common problems computationally impractical. Schellekens ${ }^{14}$ recently suggested that in problems where failure is highly localized the displacement norm in Riks method should be determined considering only the dominant degrees of freedom. May ${ }^{18}$ describes a new automated solution procedure for structures with strain-softening materials that is based on a constraint equation that uses only the displacement parameters associated with the localized failure zone in such structures. Unfortunately, a local arc-length procedure was not available for the analyses presented here.

\section{Results and Discussion}

Four test problems were selected to validate the decohesion elements. The first problem consists of the double cantilever beam (DCB) test used to determine Mode I toughness. The second problem modeled consists of the end-notched flexure test (ENF) used for Mode II toughness. The third test is the mixed bending mode test (MMB). All three of these problems have analytical solutions that were developed by $\mathrm{Mi}$ and Crisfield $^{19}$. These closed form solutions provide an approximate framework against which to assess the FE models. The fourth test case examined is a structural problem of skin and stiffener flange debonding. 


\section{$\underline{D C B}$ Test for Mode 1}

The ASTM standard specimen used to determine the interlaminar fracture toughness in Mode $\mathrm{I}\left(G_{l C}\right)$ is the double-cantilever beam (DCB) specimen. This specimen is made of a unidirectional fiber-reinforced laminate containing a thin insert at the mid-plane near the loaded end. A $15-\mathrm{cm}$.-long specimen, $2 \mathrm{~cm}$.-wide, and composed of two 1.98-mm-thick plies of unidirectional material was tested by Morais ${ }^{20}$. The initial crack length is $5.5 \mathrm{~cm}$. The properties of the graphite material are shown in Table 1 , and the properties of the interface are shown in Table 2.

Table 1. Properties of the Graphite/Epoxy material ${ }^{20}$.

\begin{tabular}{cccccc}
\hline $\mathbf{E}_{11}$ & $\mathbf{E}_{22}=\mathbf{E}_{33}$ & $v_{12}=v_{13}$ & $v_{23}$ & $\mathbf{G}_{12}=\mathbf{G}_{13}$ & $\mathbf{G}_{23}$ \\
\hline $150 . \mathrm{MPa}$ & $11 . \mathrm{MPa}$ & 0.25 & 0.45 & $6.0 \mathrm{MPa}$ & $3.7 \mathrm{MPa}$ \\
\hline
\end{tabular}

Table 2. Properties of the DCB specimen interface ${ }^{20}$.

\begin{tabular}{ccccc}
\hline $\mathbf{G}_{\mathrm{lc}}$ & $\mathbf{G}_{\mathrm{llc}}$ & $\mathbf{T}$ & $\mathbf{S}$ & $\boldsymbol{K}_{P}$ \\
\hline $0.268 \mathrm{~N} / \mathrm{mm}$ & $1.45 \mathrm{~N} / \mathrm{mm}$ & $30 . \mathrm{MPa}$ & $40 . \mathrm{MPa}$ & $10^{6} \mathrm{~N} / \mathrm{mm}^{3}$ \\
\hline
\end{tabular}

Using Eqs. 9 and the properties of the interface shown in Table 2, the relative Mode I and Mode II displacements for damage onset are $\delta_{I}^{0}=30 \times 10^{-6} \mathrm{~mm}$. and $\delta_{I I}^{0}=40 \times 10^{-6} \mathrm{~mm}$., respectively. The corresponding ultimate relative displacements calculated from Eqs. 11 are $\delta_{l}^{F}=17.9 \times 10^{-3} \mathrm{~mm}$. and $\delta_{l l}^{F}=72.5 \times 10^{-3} \mathrm{~mm}$.

The ABAQUS finite element model, which is shown deformed in Figure 7 , consists of two layers of C3D8I incompatible-mode 8-noded elements. C3D8I elements are superior in bending to other low-order continuum elements. The anticlastic effects were neglected and only one element was used across the width. One hundred and twenty elements were used along the span of the model shown in Figure 7.

A plot of reaction force as a function of the applied end displacement $d$ is shown in Figure 8. The beam solution was developed by Mi and Crisfield ${ }^{19}$ for isotropic adherend materials and using plane stress assumptions. Note that the beam solution is somewhat stiffer than the test and FEM results which is probably due to the assumption of isotropy in the analytical solution. After the initiation of delamination, fiber bridging in the test specimen causes a small drift in the response compared to the FEM and analytical solutions.

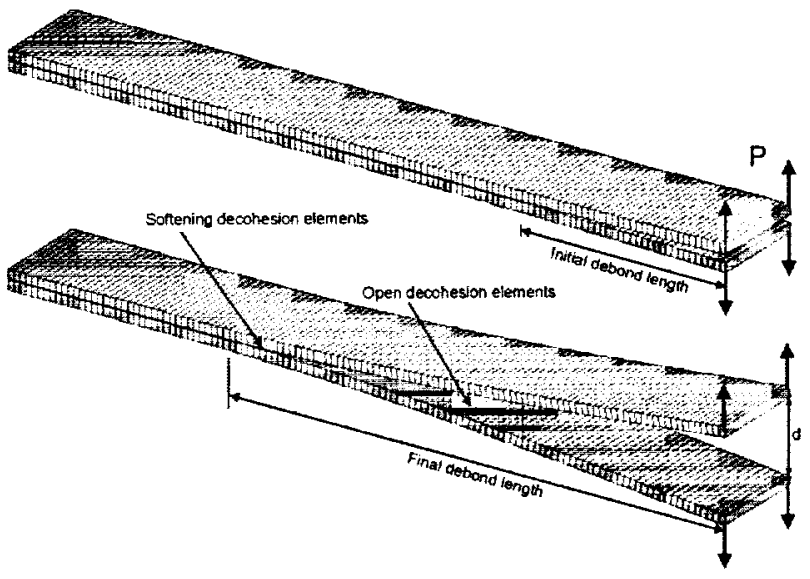

Figure 7. Model of DCB test specimen.

Numerical studies with different element sizes indicate that the accuracy of the prediction can be significantly lower if the size of the elements used in the softening zone is greater than some maximum value. The maximum predicted load sustained by the DCB specimen calculated using several mesh densities is shown in Figure 9. The results indicate that poor results are obtained for this problem when the element size is greater than $1.25 \mathrm{~mm}$. This mesh size is consistent with the results of Gonçalves ${ }^{9}$, who used 1-mm.-long 18node quadratic elements for the analysis of a DCB specimen.

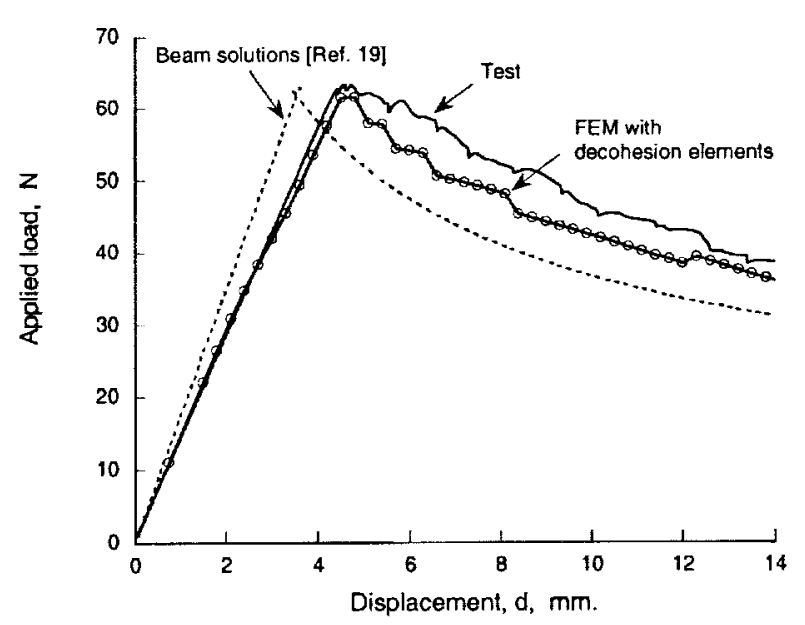

Figure 8. Load-deflection response of DCB test. 


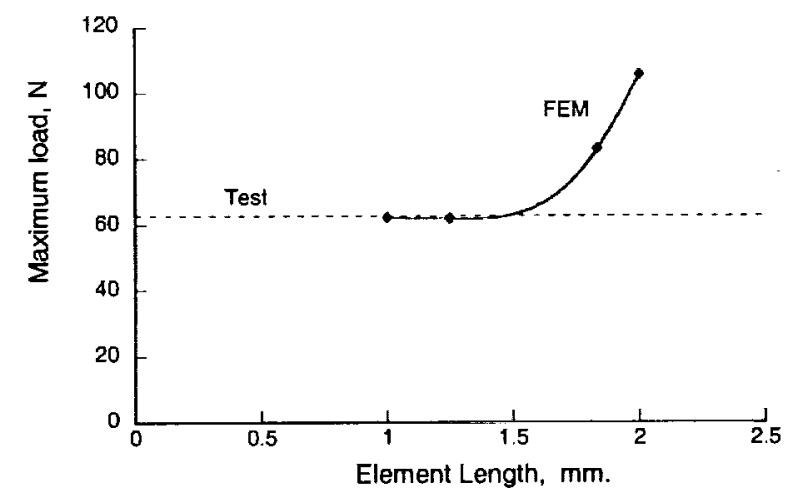

Figure 9. Debond load as a function of element size.

\section{$\underline{\text { ENF Test for Mode II }}$}

Even though the end-notched flexure test specimen shown in Figure 10 exhibits unstable crack propagation for short crack lengths, its simplicity makes it a common test to measure Mode II fracture toughness. The length of the specimen modeled here is $10 \mathrm{~cm}$., its width is $1 \mathrm{~cm}$., and the initial debond length is $3 \mathrm{~cm}$. Aluminum adherends were used rather than composite to achieve a closer approximation to the analytical solutions calculated by $\mathrm{Mi}^{19}$. The thickness of the adherends is $1.5 \mathrm{~mm}$. The properties of the interface are the same as for the DCB model.

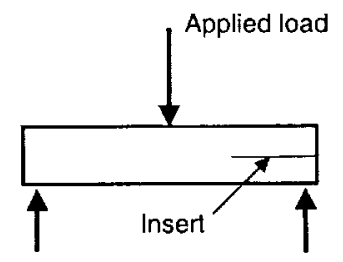

Figure 10. ENF test specimen.

The load-deflection responses for the finite element model and the analytical prediction are shown in Figure 11. It can be observed that both solutions are in excellent agreement.

\section{Mixed Mode Bending Test}

The most widely used specimen for mixed-mode fracture is the mixed-mode bending (MMB) specimen shown in Figure 12, which was proposed by Reeder and Crews $^{21}$ and later re-designed to minimize geometric nonlinearities ${ }^{22}$. The main advantages of the MMB test method are the possibility of using virtually the same specimen configuration as for Mode I tests and varying the mixed mode ratio from pure Mode I to pure Mode II.

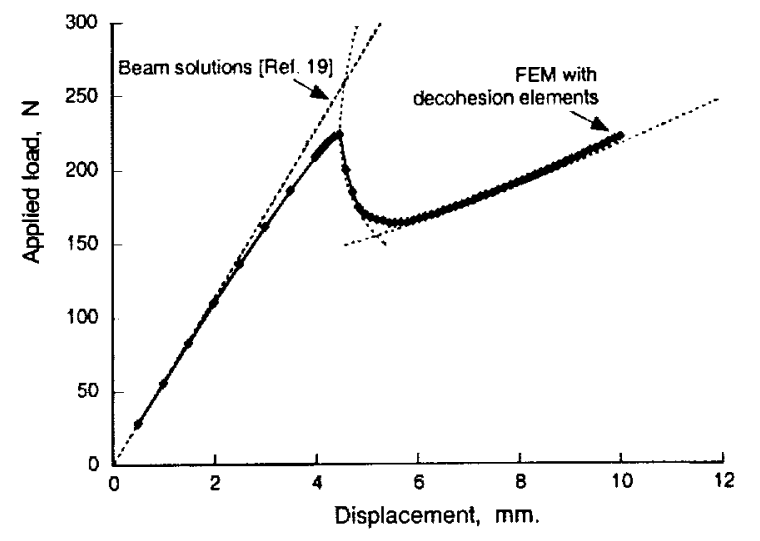

Figure 11. Analytical and FEM load-deflection curves for ENF test.

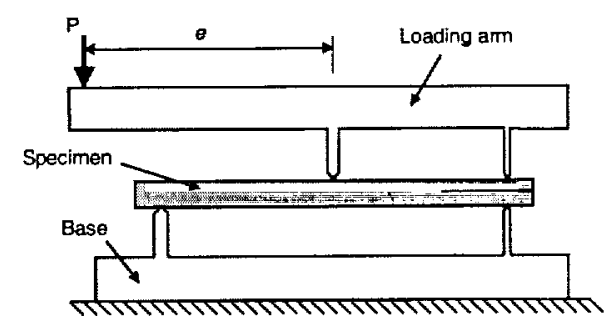

Figure 12. MMB test specimen.

The specimen analyzed here has a length of $10 \mathrm{~cm}$., a width of $1 \mathrm{~cm}$, and an initial debond length of $3 \mathrm{~cm}$. The thickness of the aluminum adherends is $1.5 \mathrm{~mm}$. The properties of the interface are the same for the DCB and ENF models. The length of the MMB lever $e$ was chosen as $43.72 \mathrm{~mm}$, which corresponds to a ratio of 1 for $G_{l} / G_{I I}$ and to a ratio of 2.14 between the load at the mid-span of the beam and the opening load. The MMB load fixture is simulated by applying an opening load of $100 \mathrm{~N}$. at the edge of the debond, and an opposite load of $214 \mathrm{~N}$. at the mid-span of the beam.

The model is composed of two layers of 100 C3D8I solid elements. A deformed plot of the finite element model is shown in Figure 13.

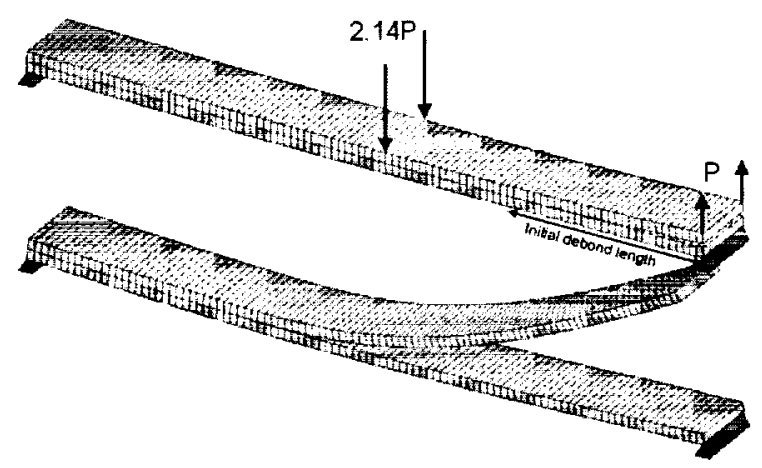

Figure 13. Deformed plot of MMB Model. 
The load deflection curve calculated from FEM and two beam solutions from Ref. 19 are shown in Figure 14. One beam solution assumes a quadratic interaction between the energy release rates, and the other assumes a linear interaction. No test results were available for the configuration analyzed. Reasonably good correlation is obtained among all three methods.

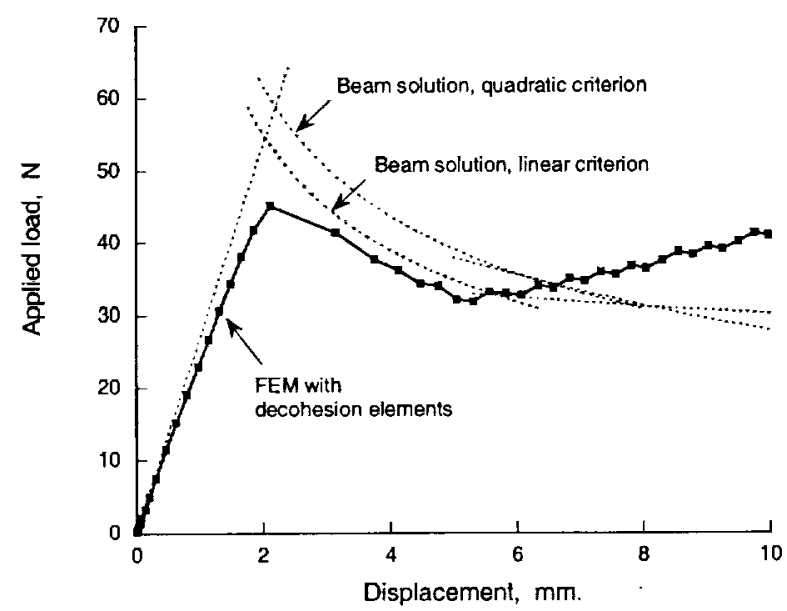

Figure 14. Load-deflection plot for MMB test.

\section{Skin-Flange Debonding}

As was mentioned earlier in this paper, the objective of the present work is to develop a methodology that can predict non-self-similar delamination growth without user intervention such as for remeshing or for releasing constraint equations. The effectiveness of the methodology for modeling common structural problems without unusually high computational or modeling costs is assessed.

To evaluate the use of decohesion elements in structural problems, a problem involving skin-stiffener flange debonding was selected. Extensive testing of this problem has been performed by Cvitkovich and $\mathrm{O}^{\prime} \mathrm{Brien}^{23,24}$, and analyses have been conducted by Krueger and O'Brien ${ }^{25}$. The configuration of the specimens studied in Refs. 23 and 25 is shown in Figure 15. The specimens are $203 \mathrm{~mm}$.-long, $25.4 \mathrm{~mm}$.-wide. Both skin and flange were made from IM6/3501-6 graphite/epoxy prepreg tape with a nominal ply thickness of $0.188 \mathrm{~mm}$. The skin lay-up consisting of 14 plies was $[0 / 45 / 90 /-45 / 45 /-45 / 0]_{\mathrm{s}}$ and the flange lay-up consisting of 10 plies was $[45 / 90 /-45 / 0 / 90]_{s}$.

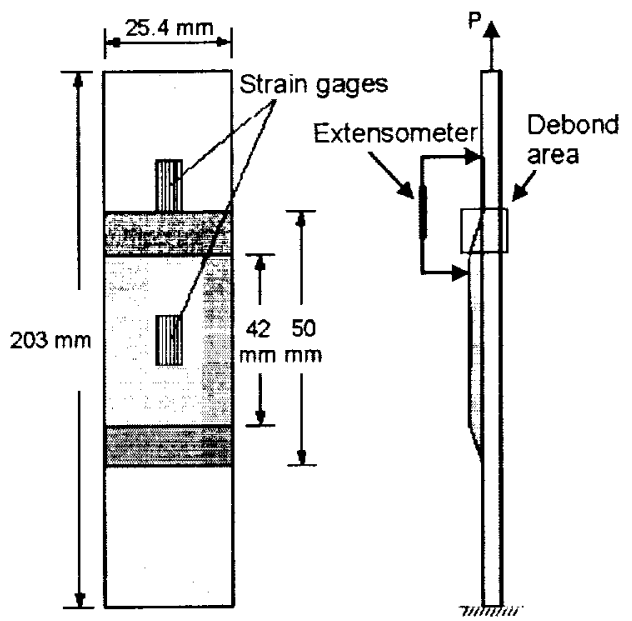

Figure 15. Skin-stiffener specimen configuration.

Reference 25 describes the complexities of this problem, such as the presence of several interacting failure modes, a non self-similar crack growth, crack fronts that jump between plies and do not remain at a single interface. References 23 and 25 also show that delamination seldom initiates or grows between the flange and the skin, but rather on a surface one or two plies away from the skin-flange interface. A photo micrograph taken from Ref. 23 and shown in Figure 16 shows these features.

The properties of the unidirectional graphite/epoxy and the properties of the interface reported in Ref. 25 are shown in Tables 4 and 5, respectively.

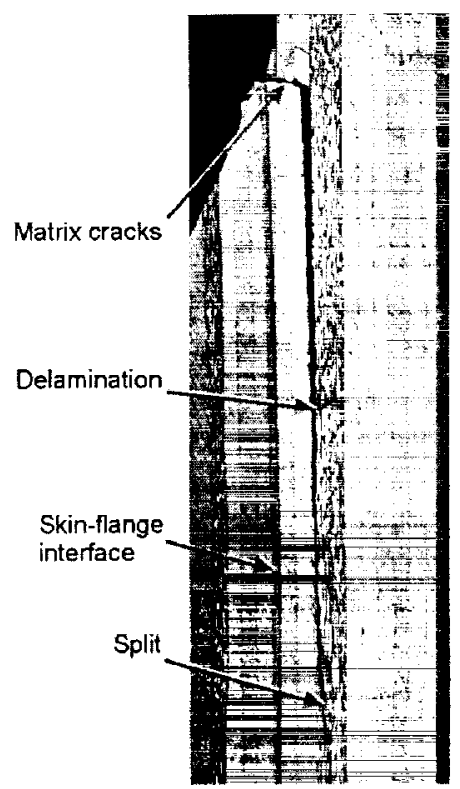

Figure 16. Detail of debond area in a failed $\operatorname{specimen}^{24}$. 
Table 4. Material Properties ${ }^{25}$.

IM6/3501-6 Unidirectional Graphite/Epoxy.

\begin{tabular}{cccccc}
\hline $\mathbf{E}_{11}$ & $\mathbf{E}_{22}=\mathbf{E}_{33}$ & $v_{12}=v_{13}$ & $v_{23}$ & $\mathbf{G}_{12}=\mathbf{G}_{13}$ & $\mathbf{G}_{23}$ \\
\hline $144.7 \mathrm{MPa}$ & $9.65 \mathrm{MPa}$ & 0.3 & 0.45 & $5.2 \mathrm{MPa}$ & $3.4 \mathrm{MPa}$ \\
\hline
\end{tabular}

Table 5. Properties of the interface ${ }^{25}$.

\begin{tabular}{cccc}
\hline $\mathbf{G}_{\text {Ic }}$ & $\mathbf{G}_{\text {IIc }}$ & $\mathbf{T}$ & $\mathbf{S}$ \\
\hline $0.075 \mathrm{~N} / \mathrm{mm}$ & $0.60 \mathrm{~N} / \mathrm{mm}$ & $61 \mathrm{MPa}$ & $68 \mathrm{MPa}$ \\
\hline
\end{tabular}

The relative Mode I and Mode II displacements for damage onset calculated using Eqs. 9 and the interface properties shown in Table 5 are $\delta_{l}^{0}=61 . \times 10^{-6} \mathrm{~mm}$. and $\delta_{l l}^{0}=68 . \times 10^{-6} \mathrm{~mm}$., respectively. The corresponding ultimate relative displacements calculated from Eqs. 11 are $\delta_{I}^{F}=2.46 \times 10^{-3} \mathrm{~mm}$. and $\delta_{I I}^{F}=17.5 \times 10^{-3} \mathrm{~mm}$.

A complete analysis of the delamination growth in the tension specimen requires a high degree of complexity. For instance, Krueger ${ }^{25}$ developed highly detailed two-dimensional models using up to four elements per ply thickness. Krueger modeled discrete matrix cracks and delaminations including the specific paths followed by the delamination in particular section planes.

The approach taken here, on the other hand was to determine if it is possible to predict the debond load of the specimen using decohesion elements in a much coarser three-dimensional model. To keep the modeling difficulties low and the approach applicable to larger problems, the model that was developed uses only two brick elements through the thickness of the skin, and another two through the flange. It is implied from such a simplified geometry that the interaction between the skin and the flange is the physical mechanism that leads to the debonding of the flange. The complete model consists of 1,002 three-dimensional 8-noded C3DI elements and 15,212 degrees of freedom. To prevent delamination from occurring at both ends of the flange simultaneously, model symmetry was reduced by modeling the tapered end of the flange with a refined mesh on one side and a coarser mesh on the other. This model does not contain any pre-existing delaminations.

Unsymmetric layered properties were assigned to the three-dimensional elements by using the composite solid section option in ABAQUS. The option calculates the element's stiffness by performing a Simpson's integration through the thickness using material points in each of the plies within the element. Gaussian integration is used in the lamination planes of the element. Approximations to the lamination planes were necessary in the tapered sections of the flange because planes of integration cannot be defined parallel to the plies in the tapered elements.

Deformed plots of the finite element model immediately before and after flange separation are shown in Figure 17. It can be observed that only the refined end of the flange separates. A detailed analysis of the results indicated that the coarse end of the flange also softens, but that the separation of the flange at the refined end relieves the stresses at the coarse end. It is interesting to note that static tests exhibit debond of only one end. Fatigue tests, on the other hand, induce debonding at both ends.

Note that the debond growth is not symmetric: the debond initiates on the left corner of the flange shown on the top of Figure 17 due to the unsymmetry introduced by the terminated plies at the flange tapered ends. Cvitkovich also commented on the difference that he observed in the modes of failure of the two corners ${ }^{23}$.

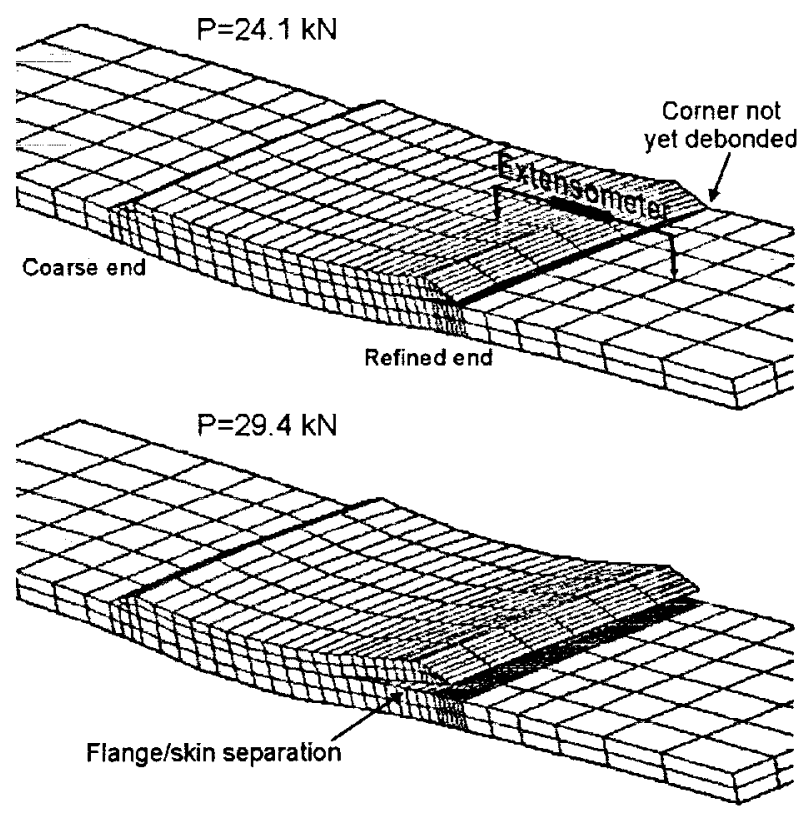

Figure 17. Deformed plots of skin/flange debond model at applied loads of 24.1 and $29.4 \mathrm{kN}$.

The axial strains for the two gages shown in Figure 15 are shown in Figure 18. The strains and the failure load predicted by the model correlate well with the test results. However, the test results after the debond load are misleading because the load was immediately reversed after failure by the test operator, even if the specimen could carry additional loads. 


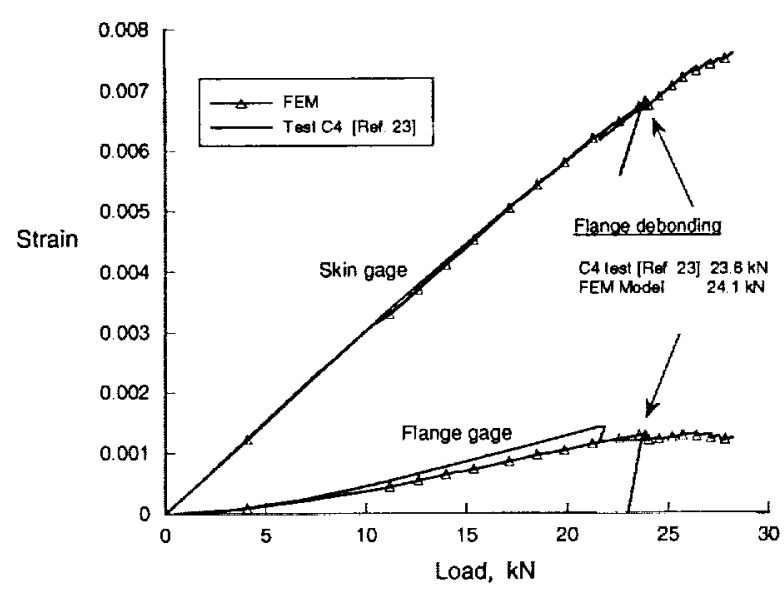

Figure 18. Strains at two gage locations for test and models with and without ply damage

The extensometer measurements for tests $\mathrm{C} 4, \mathrm{C} 6$, $\mathrm{C} 8$ and $\mathrm{C} 10$ conducted by Cvitkovich ${ }^{23}$ and the predicted values are shown in Figure 19. The initiation of delamination is marked by the sharp breaks in the extensometer readings. After failure, the extensometer measurements are unreliable, as can be observed by comparing the different tests. The predicted response correlates well with the experimental results. The predicted debond load is just outside the range for all four tests.

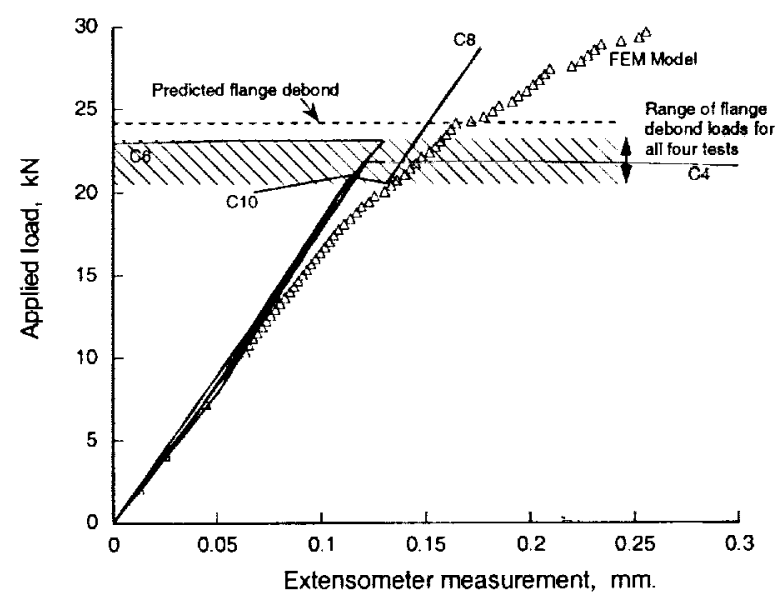

Figure 19. Predicted and experimental extensometer measurements.

\section{Concluding Remarks}

A method for the simulation of progressive delamination based on decohesion elements was presented. Decohesion elements are placed between layers of solid elements and they open in response to the loading situation. The onset of damage and the growth of delamination can be simulated without previous knowledge about the location, the size, and the direction of propagation of the delaminations. A strain softening law for mixed-mode delamination was proposed. The criterion uses a single state variable, the maximum relative displacement $\delta_{m}^{\text {mitax }}$, to track the damage at the interface under general loading conditions. The material properties required to define the element constitutive equation are the interlaminar fracture toughnesses and the corresponding strengths.

Four examples were presented that test the accuracy of the method. Simulations of the DCB and ENF test represent cases of single-mode delamination. The MMB test that was simulated has equal Mode I and Mode II. The skin/stiffener debond problem was used as a test of the capabilities of the method in an important structural problem that exhibits non selfsimilar delamination growth. The examples analyzed indicate that the method of decohesion elements can predict the strength of composite structures that exhibit progressive delamination.

\section{References}

1) Dávila, C.G., and Johnson, E.R., "Analysis of Delamination Initiation in Postbuckled DroppedPly Laminates," AIAA Journal, Vol. 31, No. 4, 1993, pp. 721-727.

2) Camanho, P.P., and Matthews, F.L., "Delamination Onset Prediction in Mechanically Fastened Joints in Composite Laminates," Journal of Composite Materials, Vol. 33, No. 10, 1999, pp. 906-927.

3) Rybicki, E.F., and Kanninen, M.F., "A Finite Element Calculation of Stress Intensity Factors by a Modified Crack Closure Integral," Engineering Fracture Mechanics, Vol. 9, 1977, pp. 931-939.

4) Barenblatt, G.I., "Mathematical Theory of Equilibrium Cracks in Brittle Failure," Advances in Applied Mechanics, Vol. 7, 1962.

5) Hillerborg, A., Modeer, M., and Paterson, P.E., "Analysis of Crack Formation and Crack Growth in Concrete by Fracture Mechanics and Finite Elements," Cement and Concrete Research, Vol. 6, 1976, pp. 773-782.

6) Needleman, A., "A Continuum Model for Void Nucleation by Inclusion Debonding," Journal of Applied Mechanics, Vol. 54, 1987, pp. 525-531.

7) de Moura, M.F.S.F., Gonçalves, J.P.M., Marques, A.T., and de Castro, P.M.S.T., "Prediction of Compressive Strength of Carbon-Epoxy Laminates Containing Delamination by Using a Mixed-Mode 
Damage Model," Composite Structures, Vol. 50, 2000, pp. 151-157.

8) de Moura, M.F.S.F., Gonçalves, J.P.M., Marques, A.T., and de Castro, P.M.S.T., "Modeling Compression Failure after Low Velocity Impact on Laminated Composites Using Interface Elements," Journal of Composite Materials, Vol. 31, 1997, pp. 1462-1479.

9) Gonçalves, J.P.M., de Moura, M.F.S.F., de Castro, P.M.S.T., and Marques, A.T., "Interface Element Including Point-to-Surface Constraints for ThreeDimensional Problems with Damage Propagation," Engineering Computations, Vol. 17, No. 1, 2000, pp. 28-47.

10) Petrossian, Z., and Wisnom, M.R., "Prediction of Delamination Initiation and Growth from Discontinuous Plies Using Interface Elements," Composites Part A: Applied Science and Manufacturing, Vol. 29, No. 5-6, 1998, pp. 503515.

II) Reddy, J.N., Mello, F.J., and Guess, T.R., "Modeling the Initiation and Growth of Delaminations in Composite Structures," Journal of Composite Materials, Vol. 31, 1997, pp. 812831.

12) Rice, J.R., "A Path Independent Integral and the Approximate Analysis of Strain Concentration by Notches and Cracks," Journal of Applied Mechanics, 1968, pp. 379-386.

13) Schellekens, J.C.J., and de Borst, R., "Numerical Simulation of Free Edge Delamination in GraphiteEpoxy Laminates under Uniaxial Tension," Proceedings of the 6th International Conference on Composite Structures, 1991, pp. 647-657.

14) Schellekens, J.C.J., and de Borst, R., "On the Numerical Integration of Interface Elements," International Journal for Numerical Methods in Engineering, Vol. 36, 1993, pp. 43-66.

15) Chen, J., Crisfield, M.A., Kinloch, A.J., Busso, E.P., Matthews, F.L., and Qiu, Y., "Predicting Progressive Delamination of Composite Material Specimens Via Interface Elements," Mechanics of Composite Materials and Structures, Vol. 6, 1999, pp. 301-317.

16) Mi, Y., Crisfield, M.A., Davies, G.A.O., and B., H.H., "Progressive Delamination Using Interface Elements," Journal of Composite Materials, Vol. 32, 1998, pp. 1246-1273.

17) Daudeville, L., Allix, O., and Ladevèze, P., "Delamination Analysis by Damage Mechanics:
Some Applications," Composites Engineering, Vol. 5, No. 1, 1995, pp. 17-24.

18) May, I.M., and Duan, Y., "A Local Arc-Length Procedure for Strain Softening," Computers \& Structures, Vol. 64, No. 1-4, 1997, pp. 297-303.

19) Mi, Y., and Crisfield, M.A., "Analytical Derivation of Load/Displacement Relationships for MixedMode Delamination and Comparison with Finite Element Results," Imperial College, Department of Aeronautics, London, 1996.

20) Morais, A.B., Marques, A.T., and de Castro, P.T., "Estudo Da Aplicação De Ensaios De Fractura Interlaminar De Modo I a Laminados Compósitos Multidireccionais," Proceedings of the 7as Jornadas De Fractura, Sociedade Portuguesa de Materiais, Portugal, 2000, pp. 90-95.

21) Crews, J.H., and Reeder, J.R., "A Mixed-Mode Bending Apparatus for Delamination Testing," NASA TM 100662, Hampton, VA, 1988.

22) Reeder, J.R., and Crews, J.H., "Nonlinear Analysis and Redesign of the Mixed-Mode Bending Delamination Test," NASA TM 102777, Hampton, VA, 1991.

23) Cvitkovich, M.K., Krueger, R., O'Brien, T.K., and Minguet, P.J., "Debonding in Composite Skin/Stringer Configurations under Multi-Axial Loading," Proceedings of the American Society for Composites - 13th Technical Conference on Composite Materials, Baltimore, MD, September 21-23, 1998, pp. 1014-1048.

24) Cvitkovich, M.K., O'Brien, T.K., and Minguet, P.J., "Fatigue Debonding Characterization in Composite Skin/Stringer Configurations," NASA TM110331, Hampton, VA, 1997.

25) Krueger, R., Cvitkovich, M.K., O'Brien, T.K., and Minguet, P.J., "Testing and Analysis of Composite Skin/Stringer Debonding under Multi-Axial Loading," Composite Materials, Vol. 34, No. 15, 2000, pp. 1263-1300. 